\title{
The orang-utan in Sabah
}

Glyn Davies

A survey of orang-utans in Sabah, Borneo, which was carried out by the author and John Payne, resulted in an encouraging picture. In the primary forest of eastern Sabah alone, there are at least $\mathbf{4 0 0 0}$ orang-utans, but habitat destruction is fragmenting the population. Hunting is also common, especially in the central and western areas where orangutans are already scarce. Some orang-utans are protected in conservation areas, but the future of the species outside these places depends on logging being carried out in a more conservation-oriented way. Among other things, we need to discover the size of primaryforest patches that need to be left in logged forest to support a viable population of orangutans, which will be able to recolonize the logged forest as it regenerates.

The orang-utan Pongo pygmaeus is Asia's great ape and it occurs on only two islands in SouthEast Asia. On Sumatra it is restricted to upland forests in the northern part of the island, but the species is more widespread in Borneo (Rijksen, 1978). One area in Bomeo where the orang-utan has attracted much attention is Sabah, the State occupying the northern $76,115 \mathrm{sq} \mathrm{km}$ of the island. During the 1960s, surveys and ecological studies revealed dense populations of orangutans in some regions (Davenport, 1967; MacKinnon, 1971; Horr, 1972), and some areas were recommended for conservation of the species. These recommendations came to little, however, and there have been drastic changes in land use over the last 20 years. As a result, in 1979 the Wildlife Section of the Sabah Forest Department initiated a faunal survey of the State to investigate the distribution and abundance of 40 mammal populations, paying particular attention to large, endangered species such as the orangutan. The survey was co-ordinated by two investigators who were funded by the World Wildlife Fund Malaysia (Payne and Davies, 1982).

Orang-utans are shy animals and are difficult to see in the dense vegetation of the rain forest, despite their large size and red pelage. They tend not to live in large family groups, but occur singly or in small parties of two to five animals. There are several features of the animals' biology, however, that aid their location. Adult male orang-utans give loud roaring calls, and animals of all ages, excluding the smallest infants, give squeals and 'kiss-squeaks' when alarmed. They also make loud rustling sounds in branches as they travel between tree crowns. Occasionally, the larger animals travel along the ground and leave footprints. Furthermore, all independent animals build a nest-platform to sleep in each night, which, if it is recently built, indicates the presence of orang-utans in an area.

During the two-and-a-half year project, all sightings of orang-utans, their signs and reliable reports of their presence were recorded. In addition, detailed information was collected on orang-utan population densities at 20 sites during surveys, which lasted between six and nine days. At each site an 80-m-wide transect of forest was surveyed. This transect width represented the distance either side of a trail over which primates could be reliably detected by an observer walking slowly through the forest. Too few data were collected to make a statistical assessment of the accuracy of the population density estimates Oryx Vol 20 No 1, January 1986 


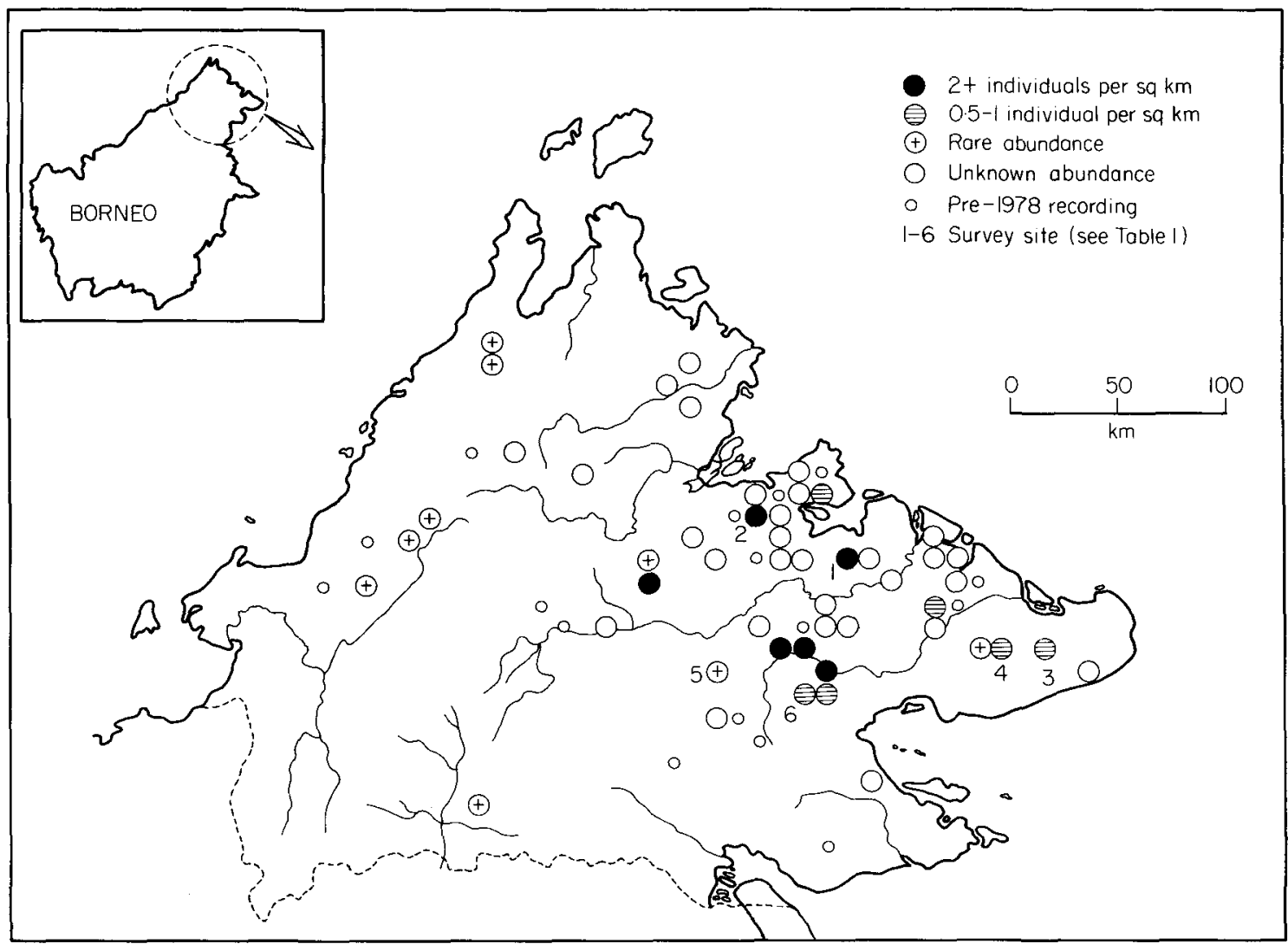

Figure 1. Distribution and abundance of orang-utans in Sabah.

obtained using this method, but the results from three survey sites tallied closely with those obtained during long-term studies of orang-utans in the same areas.

\section{The orang-utan population}

A map of the distribution of orang-utans within Sabah (Figure 1) is encouraging, in that it shows that the species is still widely distributed. Few surveys were made to the poorly accessible south/central part of Sabah and so records from this region are incomplete, but there is no reason to expect orang-utans to be absent, although they may be scarce.

The densest populations were found in primary forests of the eastern lowlands (less than $150 \mathrm{~m}$ above sea level) where there were up to two orang-utans per sq $\mathrm{km}$. At other sites in the eastern region (less than $450 \mathrm{~m}$ above sea level) population densities ranged from 0.5 to 1 individual per sq $\mathrm{km}$. Orang-utan populations in The orang-utan in Sabah
Sabah become sparser with increasing altitude (Figure 2), and they were so scarce in the highlands of western Sabah that it was impossible to estimate the numbers accurately. It is not clear to what extent this scarcity results from a decrease in the quality of forest for orang-utans as altitude increases, or how much hunting, which is common in western areas, has a negative effect.

Applying the above estimates of population density to primary forest areas in eastern Sabah (about $5000 \mathrm{sq} \mathrm{km}$ ), it is calculated that there are at least 4000 orang-utans in this area. There are some more orang-utans in the central region of the State, which was less thoroughly surveyed, but very few occur in the western areas. Overall, therefore, there is a substantial population of orang-utans in Sabah, which provides ample scope for conservation of the species.

\section{Threats to the species}

Although the large number of orang-utans found 
in Sabah is encouraging, the population is decreasing in size and is being fragmented. The main pressures on the population are hunting, habitat degradation through commercial selective felling, and loss of forest to agricultural schemes.

\section{Hunting}

In western and south-western Sabah, local people hunt orang-utans for food. This is a mountainous area where orang-utans are scarce, and there are many places where the species has been eliminated by hunting practices. A similar situation has been described for parts of neighbouring Sarawak (Medway, 1970). Recently, with the introduction of shotguns, the intensity of hunting has increased all over the State. In the east, timber-camp employees and town-dwellers occasionally shoot orang-utans for 'sport'. Law enforcement by the Forest Department has controlled hunting in these areas, but little can be done in the more remote central and western regions.

\section{Timber extraction}

Over 50 per cent of Sabah has been selectively logged, which, in conjunction with agricultural

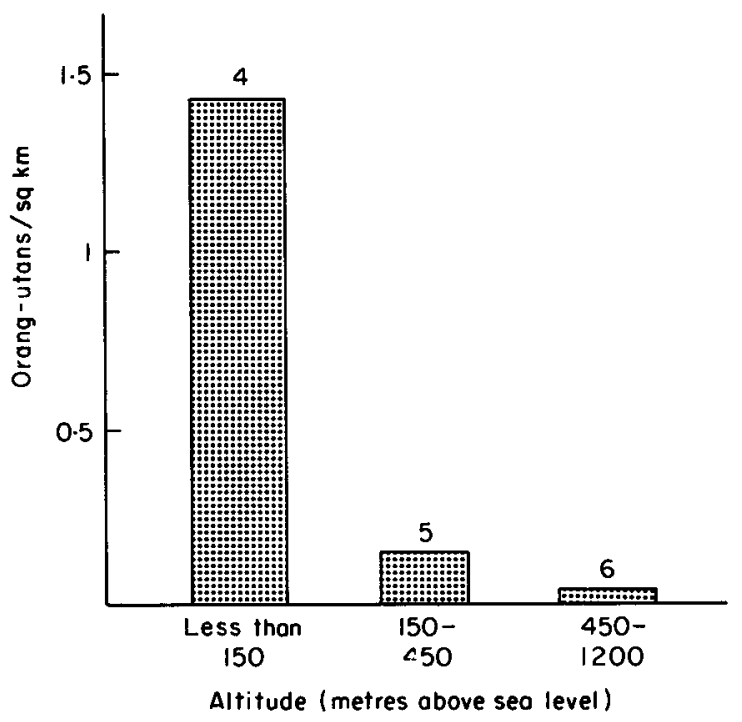

Figure 2. Average population densities of orang-utans at different altitudes in Sabah. Numbers refer to the number of sites that were surveyed from each altitudinal zone. schemes, leaves only one-third of the State covered by primary forest, mainly in south/ central areas. The effects of timber extraction on orang-utans in Sabah were assessed during six surveys in the eastern part of the State. Two surveys were made in Virgin Jungle Reserves, which are isolated primary forest areas of less than 500 ha surrounded by logged forest. Four surveys were made in two pairs in two regions: one survey from each pair was done in logged forest 15-20 years after timber had been extracted, and the other in nearby primary forest (see Table 1).

One immediate effect of timber extraction is that a small number of orang-utans are killed during felling. Most, however, emigrate to areas of undisturbed forest, even if this results in crowding. The population densities recorded in the two Virgin Jungle Reserves were twice as high as expected for the region, especially since surveys in the same areas revealed low orangutan population densities in the 1960s (Harrisson, 1963).

In cases where orang-utans migrate to large tracts of primary forest, the resident populations tend to become overcrowded by this influx from logged forests. This, in turn, may result in a decline in birth rate (MacKinnon, 1972). Thus, while the migration of orang-utans may reduce immediate fatalities, stable populations are unlikely to be bolstered in the long-term by immigration.

Once timber extraction has ceased, many areas of logged forest in Sabah are left to regenerate. Surveys of logged forest in an area where orangutans were probably abundant prior to logging (for example, Malubuk) revealed that some orang-utans did occur in the logged forest, although at much lower densities than in primary forests of the same region. In areas where orangutans were probably only moderately common prior to logging (for example, Bakapit) none were recorded in logged forest. Overall, therefore, the species is particularly vulnerable to changes in its habitat and is largely dependent on primary forests for its survival.

It is encouraging that some orang-utans occur in a few logged forests, but it is unclear whether these animals have always been in the areas or have Oryx Vol 20 No 1, January 1986 
Table 1. The influence of timber extraction on orang-utan populations in Sabah (surveys made in 1980/81)

\begin{tabular}{lcll}
\hline Survey site & $\begin{array}{l}\text { Altitude } \\
(\mathrm{m})\end{array}$ & Habitat & $\begin{array}{c}\text { Population density } \\
\text { (individuals per sq km) }\end{array}$ \\
\hline 1. Gomantong & 30 & Virgin Jungle Reserve & 3.9 \\
2. Lungmanis & 40 & Virgin Jungle Reserve & 4.1 \\
3. Bakapit & 150 & Logged in 1962 (8 per ha*) & 0 \\
4. Tabin & 170 & Primary forest & $?$ \\
5. Malubuk & 220 & Logged in 1965 (10 per ha*) & $?$ \\
6. Kawag & 220 & Primary forest & 1.0 \\
\hline
\end{tabular}

?, Present but rare.

*, Number of trees removed.

recolonized them recently. It is also not known whether they live wholly in the logged forests or are merely passing through between patches of primary forest. More information is needed on these ecological questions, and on the breeding success of animals living in logged forests, before the usefulness of logged forests for orang-utan conservation can be fully assessed.

\section{Agriculture}

The other major form of habitat alteration is agricultural development of an area. In Sabah, traditional shifting cultivators clear small areas of forest (less than $10 \mathrm{ha}$ ), burn the trees and plant hill rice and fruit trees for about three years before moving on. This results in a mosaic of habitats, to which orang-utans can adapt as long as the hunting pressure, which often accompanies shifting cultivation, is not too great. Unfortunately, orang-utans feed from fruit trees that are near forest edges on occasions and are consequently shot as pests.

As the scale of forest clearance and burning increases, so the ability of orang-utans to use the area decreases. As a result, few orang-utans have been recorded in western areas of Sabah, where settled agriculturalists clear and burn large areas of hill forest for rice. Similarly, modem agricultural development, for which over 30 per cent of Sabah is suitable, involves the clear felling and burning of many hundreds of hectares. The initial burning of vegetation eliminates all wildlife, and orang-utans do not feed to any great extent on the cash crops that are subsequently planted. Unfortunately, the best agricultural land in Sabah The orang-utan in Sabah is found in the eastern lowlands, where the densest populations of orang-utans have been found and where some orang-utans survive in logged forests.

\section{Conservation}

The deleterious effects of hunting, timber extraction and agricultural development mean that the only way to preserve orang-utans is by setting aside areas of primary forest where there is little hunting. Only small populations of orang-utans, however, are represented in the present conservation areas in Sabah (Figure 3).

At Sepilok, an Orang-Utan Centre was established in 1964 with the aim of reintroducing captive orang-utans into the wild (de Silva, 1970). Although there are many problems in rehabilitating orang-utans (Aveling and Mitchell, 1982), the Centre has an important function as a place to which confiscated animals may be taken. In addition, the Wildlife Education Centre there is important in informing local people of Sabah's wildlife and has more than 25,000 visitors each year. In terms of preserving a population of orang-utans in the long-term, however, Sepilok-only $40 \mathrm{sq} \mathrm{km}$ in area-is probably too small. The two inland national parks of Sabah, Kinabalu and Tawau Hills, also have very few orang-utans; indeed, the latter seems to have none at all.

The recently gazetted Tabin Wildlife Reserve (1205 sq km), therefore, is the only area where a population of orang-utans has legal protection. There are about $100 \mathrm{sq} \mathrm{km}$ of primary forest in this Reserve, where moderate densities of orang- 
utans have been recorded (less than one animal per sq $\mathrm{km}$ ). This situation would be greatly improved if legal protection were extended to preserve the Danum Valley area (438 sq $\mathrm{km}$ ) in eastern Sabah. This area has long been recommended for wildlife conservation since it is expected to have a large population of orangutans, it probably harbours the Sumatran rhinoceros, and it is unsuitable for agriculture. The area is within the Ulu Segama Forest Reserve and is part of the Sabah Foundation's timber concession area. Current policies of the Forest Department and the Sabah Foundation have excluded the Danum Valley from immediate plans for timber exploitation, and if these policies can be realized in terms of long-term legal protection, the preservation of Sabah's orang-utans should be assured.

In the future, large areas of Borneo that are unsuitable for agriculture will be covered by logged forest. It has been noted that some primates can survive selective logging of dipterocarp forests in South-East Asia, and that ungulates may prefer logged areas to primary forests (Johns, 1983), but this does not apply to orang-utans and other forest-dependent animals. It may be possible, however, to combine wildlife conservation with timber extraction if small areas of primary forest are left in logged areas. Research is needed to investigate the minimum size of primary forest areas that can support populations of animals until they can recolonize the surrounding logged areas, since this may take between 20 and 40 years. It is also necessary to examine how many primary forest areas would be needed in logged regions and at what intervals timber could be extracted from around them to ensure that no species were lost.

This information should make it possible to manage forests so that both animals that are tolerant and those that are intolerant of habitat

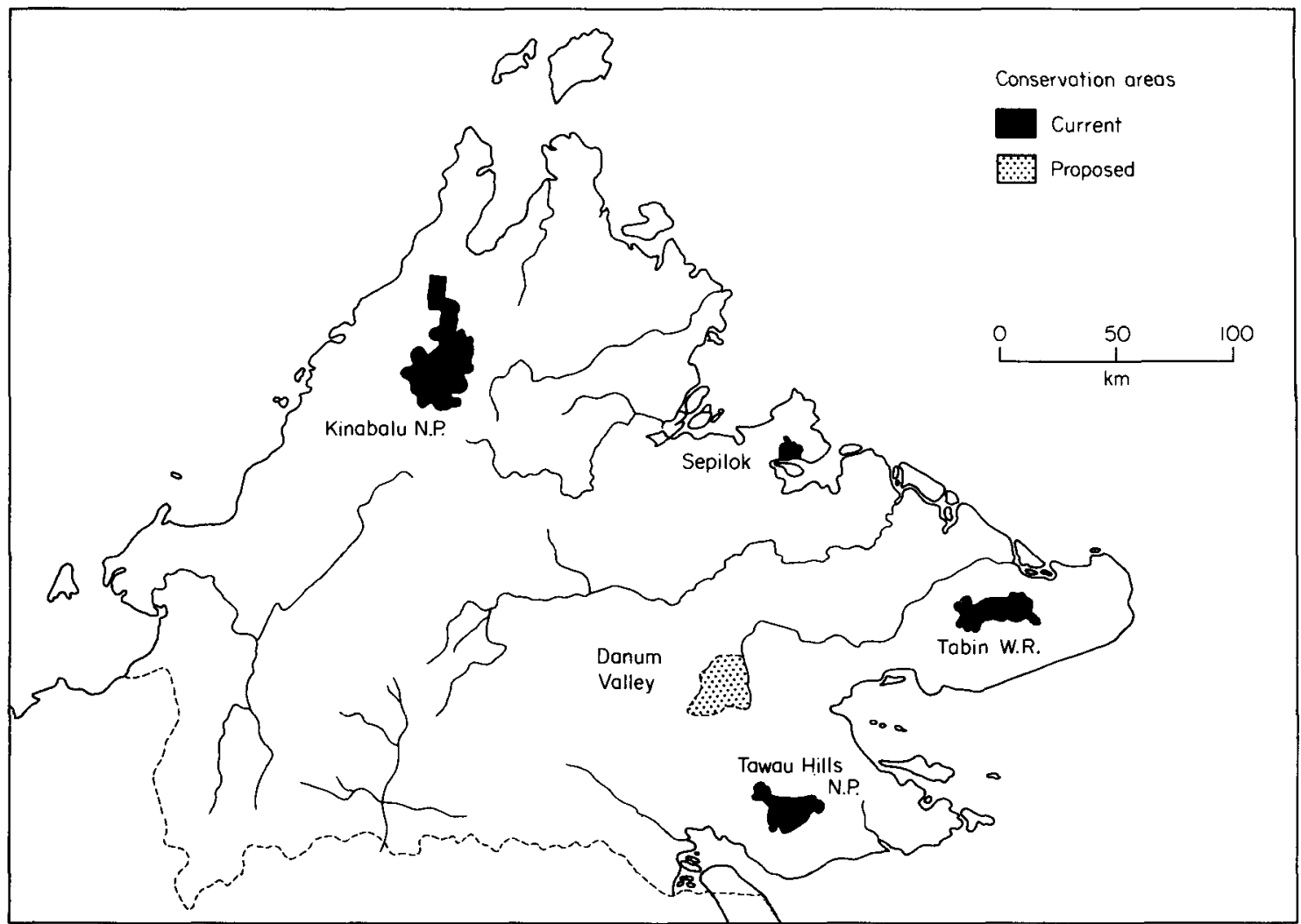

Figure 3. Current and proposed conservation areas in Sabah. 
alteration will be preserved in multiple-use forests containing a diversity of vegetation types. This will make maximum use of large tracts of logged forest for wildlife conservation. However, such a wildlife management policy can only be effective if hunting and agricultural practices in logged forests are restricted, and the temptation to cut the easily accessible primary forest patches resisted. With such imponderables, it is still imperative to set aside and maintain large areas of primary forest in order to preserve animals and plants that cannot tolerate habitat disruption. The value of logged forests that contain small primary forest reserves, however, should not be overlooked. This habitat may preserve even primaryforest dependent species, as has been shown during these surveys of orang-utans in Sabah.

\section{Acknowledgments}

The Faunal Survey of Sabah project was supported by Mr P M. Andau (Assistant Chief Wildlife Warden), and personnel of the Wildlife Section, Sabah Forest Department, participated in all surveys. Mr L. Ali (Director of Sabah National Parks) encouraged surveys in national parks, and staff from this office joined these surveys. World Wildlife Fund Malaysia sponsored the two survey co-ordinators through a donation from Tractors Malaysia Berhad. Constructive criticism of drafts of this paper was given by J. B. Payne, A. D. Johns, E. B. M.
Barrett, E. L. Bennett, G. L. Dasilva, C. W. Marsh and S. M O'Connor.

\section{References}

Aveling, R.J. and Mitchell, A. 1982. Is rehabilitating orangutans worthwhile? Oryx, XVI, 263-271.

Davenport, R.K. 1967. The orangutan in Sabah. Folia primatol. 5, 247-263.

Harrisson, B. 1963. Report of censuses in sample habitat areas of North Borneo. Unpubl. World Wildlife Fund report.

Horr, D.A. 1972. The Borneo orangutan. Bormeo Res. Bull. 4, 46-50.

Johns, A.D. 1983. Tropical forest primates and logging-can they co-exist? Oryx, XVII, 114-118

MacKinnon, J.R. 1971. The orangutan in Sabah today. Oryx, XI, $141-191$

Mackinnon, J.R. 1972. The behaviour and ecology of the orangutan (Pongo pygmaeus), with relation to other apes. D. Phil. Thesis. University of Oxford.

Medway, Lord 1970. The Mammals of Bomeo. Malaysian Branch of the Royal Asiatic Society.

Payne, J.B. and Davies, A.G. 1982. A Faunal Survey of Sabah. World Wildlife Fund Malaysia, Kuala Lumpur.

Rijksen, H.D. 1978. A Field Study of Sumatran Orangutans (Pongo pygmaeus abelli): Ecology, Behaviour and Conservation. Wageningen, Netherlands

Silva, G.S. de 1970. Training orangutans for the wild. Oryx, $\mathrm{X}$, 389-393.

Glyn Davies, Department of Biological Sciences, Njala University College, University of Sierra Leone, Private Mail Bag, Freetown, Sierra Leone.

Map showing regions used for Briefly ...

This map is based on that used by the Widllife Trade Monitoring Unit at the IUCN Conservation Monitoring Centre in Cambridge, UK.

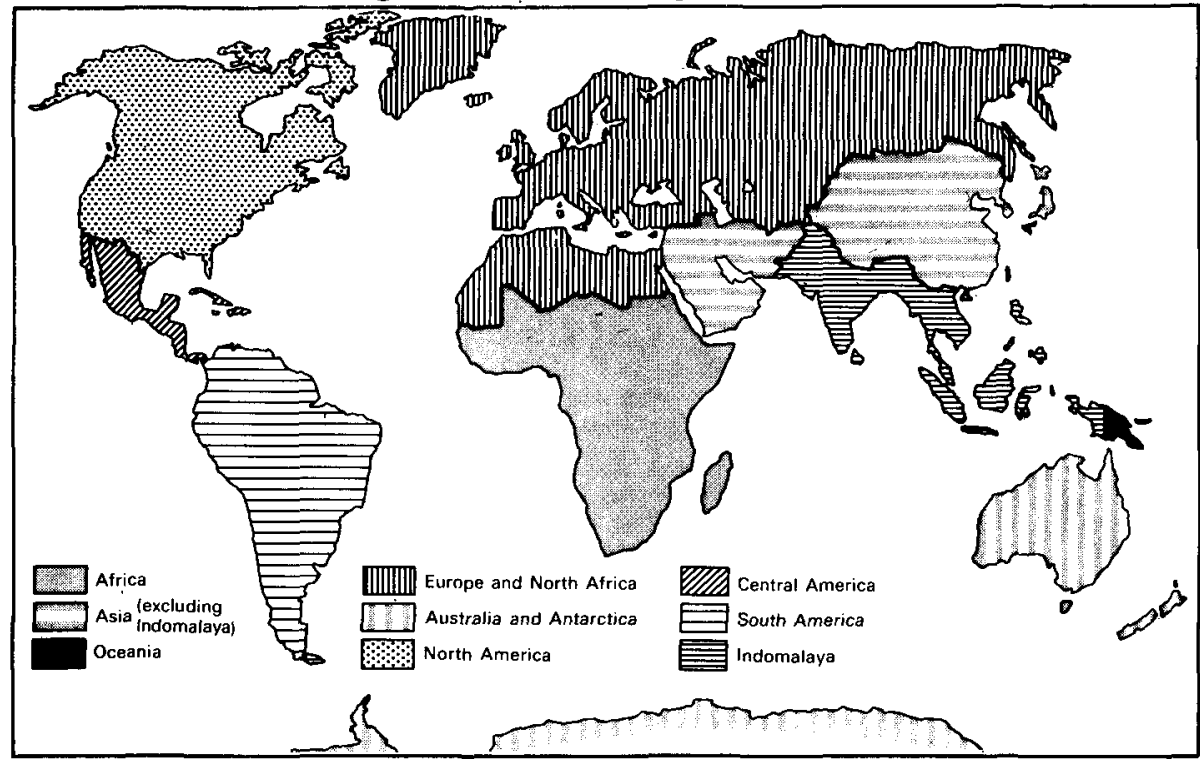

The orang-utan in Sabah 